\title{
Beyond Their HIV Status: the Occurrence of Multiple Health Risk Behavior Among Adolescents from a Rural Setting of Sub-Saharan Africa
}

\author{
Derrick Ssewanyana ${ }^{1,2}$. Charles R. Newton ${ }^{1,3} \cdot$ Anneloes van Baar ${ }^{2} \cdot$ Amin S. Hassan ${ }^{1}$ - Alan Stein ${ }^{3} \cdot$ H. Gerry Taylor ${ }^{4}$. \\ Fons Van De Vijver ${ }^{5}$. Gaia Scerif ${ }^{6}$. Amina Abubakar ${ }^{1,2,3,7,8}$
}

Published online: 25 March 2020

(C) The Author(s) 2020

\begin{abstract}
Background Health risk behaviors during adolescence may cluster into patterns that might be predicted by specific factors, among which HIV may have an important role.

Method In a cross-sectional study conducted between 2017 and 2018, clustering of HRB and its associated factors was investigated in rural Kenya among 588 adolescents (36\% perinatally HIV infected; $28 \%$ perinatally HIV exposed but uninfected; and $36 \%$ HIV unexposed/uninfected). Latent class analysis of 22 behaviors followed by multinomial logistic regression were conducted. Four risk behavior classes were identified.

Results No significant differences were found in behavioral class membership across the three HIV groups $(p=0.366)$. The risk of membership to the higher risk behavioral classes relative to class 1 (the substance and drug abstinent low risk takers) increased with older adolescent age ( $p=0.047)$, increased among adolescent who experienced mental distress $(p<0.001)$, and those who felt unsafe in their neighborhood $(p<0.002)$. Better working memory $(p=0.0037)$ was found to be protective.

Conclusion The results highlight a need to include screening and interventions for internalizing mental health problems and deficits in executive functioning, as well as steps to involve family members and communities to address psychosocial risk factors in adolescents in Kenya.
\end{abstract}

Keywords Health risk behavior $\cdot$ HIV $\cdot$ Adolescents $\cdot$ Sub-Saharan Africa $\cdot$ Latent class analysis

Derrick Ssewanyana

sewaderrick@gmail.com

1 Centre for Geographic Medicine Research Coast, Kenya Medical Research Institute (KEMRI), P. O Box 230, Kilifi 80108, Kenya

2 Utrecht Centre for Child and Adolescent Studies, Utrecht University, Utrecht, The Netherlands

3 Department of Psychiatry, University of Oxford, Oxford, UK

4 Department of Pediatrics, Center for Biobehavioral Health, Nationwide Children's Hospital Research Institute, The Ohio State University, Columbus, OH, USA

5 Department of Culture Studies, Tilburg University, Tilburg, The Netherlands

6 Department of Experimental Psychology, University of Oxford, Oxford, UK

7 Department of Public Health, Pwani University, Kilifi, Kenya

8 Institute for Human Development, Aga Khan University, Nairobi, Kenya

\section{Introduction}

The emergence of a sub-population of adolescents living with HIV, especially in Sub-Saharan Africa (SSA) [1, 2], has been met with growing research interest on health risk behavior (HRB) of this group [3, 4]. HRB is often initiated or consolidated during adolescence [5] and heightens vulnerability to sickness and mortality by compromising development and successful achievement of adolescents' expected social roles [6]. Sub-optimal HIV care and treatment outcomes like poor antiretroviral therapy (ART) adherence [7], sexually transmitted co-infections [8], and virologic failure [9] have also been linked to HRB. Most studies on HRB among adolescents living with HIV in SSA report a high prevalence (20-60\%) of risky sexual behavior and sexual victimization as well as substance use behavior, especially among males in late adolescence $[3,4]$. These findings make HRB an urgent target for intervention among adolescents living with HIV. 
Amidst the growing body of evidence on HRB of adolescents living with HIV in the SSA, most studies only report on a few forms of HRB and usually in an isolated manner [3, 4]. However, reporting of HRB in an isolated manner is not comprehensive as cross-cultural findings indicate a common tendency for multiple forms of HRB to co-occur as risk behavior clusters or bundles during adolescence [10-13]. The mechanisms explaining HRB clustering are still poorly understood and thus further research on this topic is needed [10]. Clustering refers to an observed proportion of a combination of risk factors that exceeds expectations [14]. Notably, HRB clustering or co-occurrence underlies the concept of unhealthy lifestyle [6], which also increases risk for future chronic conditions [15] and can complicate HIV treatment and care outcomes [16]. To the best of our knowledge, none of the published studies from SSA has examined HRB clustering and its underlying factors among adolescents living with HIV. There have also been observations that HRB clustering is most prevalent among disadvantaged sections of the population and that this is partly attributable to specific shared risk factors, such as social determinants of health $[2,10]$. Identifying clusters of behavior and their predictors within a sub-population can help to identify the most vulnerable adolescents and facilitate the design of more comprehensive health promotion planning and intervention programs [10]. Besides the fragmented reporting on HRB, many past studies on HRB among adolescents living with HIV in SSA lack details on response rates. Some do not clarify the route of HIV infection (i.e., vertical transmission from an HIV positive woman to her child during pregnancy, child birth or breast feeding, or horizontal transmission through contact with infected body fluids during sex or through using shared objects). Other studies do not clarify their participants' awareness of their HIV status, and a number of studies lack appropriate comparison groups [3, 4]. Studies that compare the occurrence of multiple forms of HRB in perinatally HIV-infected adolescents, to that among perinatally HIV exposed but uninfected adolescents in SSA, are inexistent.

Noteworthy, most adolescents born to HIV-infected mothers in SSA dwell in vulnerable backgrounds characterized by several familial, environmental, and biomedical factors which may adversely impact their behavioral health $[2$, $17,18]$. We hypothesize that perinatal HIV infection and exposure is associated with HRB clustering. In addition, this association could largely be explained by a combination of common risk factors experienced during adolescence and additional unique factors, resulting from perinatal HIV infection and exposure. These two sets of underlying factors for HRB are however complex to disentangle [19]. It is plausible that the additional risk from HIV-specific factors results in a heightened level of vulnerability. Therefore, a greater burden of HRB clustering among adolescents with perinatal HIV infection and exposure is expected, compared to their unaffected adolescent peers. Indeed, research from SSA settings like Kenya $[17,20]$ and South Africa [18] indicates a disproportionately greater psychosocial disadvantage among perinatally HIV-infected adolescents than the uninfected peers from similar settings.

Mental distress and other mental illness resulting from psychosocial adversity is one of the unique factors attributable to perinatal HIV infection, which may potentially heighten the risk for HRB clustering in this sub-population. Indeed, psychiatric comorbid conditions occur at high rates in people living with HIV [21]. For perinatally HIV-infected adolescents, sources of mental distress/illness often arise from recurrent and cumulative psychological stressors of coping with HIV infection, traumatic and adverse childhood experiences (e.g., loss of close family members), responsibility of taking care of siblings and ill family members, violence, stigma and discrimination, absenteeism from school, and inconsistent guardianship among others $[2,18,22,23]$. Poverty within households affected by HIV further complicates adversity of the household members [24]. Research from SSA confirms that childhood adversity heightens the risk of HRB such as risky sexual behavior and substance use among perinatally HIV-infected adolescents and youth [18]. Noteworthy, depression and other forms of mental illness like anxiety are also reported as strongly and independently associated with HRB in adolescence $[25,26]$.

Furthermore, a higher burden of poor neurocognitive functioning among perinatally HIV-infected children and adolescents (including those on HIV treatment) than that of their uninfected peers has been consistently reported in studies in SSA [27, 28] and other parts of the world [29, 30]. HIVassociated neurocognitive dysfunction has been linked to adverse effects of HIV infection [31,32] and toxicity from prolonged exposure to HIV medication (in utero, through breast milk or treatment) [33], which may cause neuropathy and thus impairment within the frontal and pre-frontal regions of the brain. Neuropathy within the prefrontal cortex regions hampers important brain maturation processes and optimal development of subtle neurocognitive abilities like executive functions (EF) [34]. Executive functions are shown to play a crucial role in behavioral regulation during adolescence [5]. Correspondingly, research findings indicate the presence of significant weaknesses in EF domains, such as working memory, planning, and inhibitory control among adolescents who engage in substance use, violence, and sexual risk behavior [35-37]. EF's significance in adolescents' risk taking has also been linked to the dual brain system of adolescence [5], characterized by a temporal lapse between onset of the socioemotional system at puberty (which increases rewardseeking tendencies) and the slower maturation of the cognitive control system (which improves individuals' capacity for selfregulation) during later adolescence. This temporal lapse explains why risk taking propensity tends to heighten at the 
onset of puberty and subsequently decline in older adolescence stage [5]. Moreover, EF deficits in planning, inhibition, working memory, cognitive flexibility, problem solving, and processing speed are increasingly reported among youth with perinatal HIV infection [30]. Other factors linked to EF outcomes include socio-economic status [38], nutritional status [39], and educational achievement [40]. We therefore hypothesize that EF deficits play an important role in predisposing perinatally HIV-infected adolescents to a high burden of HRB clustering. This stated, none of the studies on HRB of adolescents living with HIV in SSA has investigated the potential impact of EF on HRB.

Some of the commonly documented risk factors for HRB in the general adolescent population, which may also play a role in HRB clustering, include coping challenges arising from rapid cognitive, physical, social, emotional, and sexual developmental changes [5, 41]; individual level factors like religiosity, age, sex, self-esteem, and risk perception [42-44]; family level factors like substance use by close family members, household poverty, parent-adolescent connectedness, and family history of mental illness [42, 45, 46]; school environment factors [42, 47]; peer influence [43]; and neighborhood characteristics and broader/macro level factors like policy and legal framework [48, 49].

Kenya is one of the countries in SSA with a large and youthful (15-24 years) HIV sub-population that comprises $12 \%$ of the total people living with HIV [50]. Nevertheless, studies on HRB of adolescents living with HIV in Kenya barely exist. In rural settings such as coastal Kenya, a high psychosocial burden coupled with suboptimal HIV treatment and lack of health and social services exacerbate problems, faced by adolescents living with HIV [17, 51, 52]. Within such settings, adolescents living with HIV may experience high vulnerability to HRB, which may adversely impact their HIV treatment outcomes and general health. Despite these circumstances, there is still a dearth of evidence on the lifestyle of adolescents living with HIV, as well as on the general adolescent sub-population from rural Kenya. In order to reduce the existing knowledge gaps, HRB clustering was investigated in rural coastal Kenya among perinatally HIV infected, perinatally HIV exposed but uninfected, and HIV unexposed and uninfected adolescents. We explored the extent to which perinatal HIV infection influences HRB clustering during adolescence, while controlling for relevant confounding factors tested in a directed acyclic graph (DAG).

\section{Methods}

\section{Participants and Procedures}

The first wave of data collection was conducted between November 2017 and October 2018, providing a baseline assessment for the ongoing longitudinal study, the Adolescent Health Outcomes Study (AHOS). The study was conducted at the Centre for Geographic Medicine ResearchCoast at the Kenya Medical Research Institute (CGMRCKEMRI) and all the participants were residents of Kilifi County at the coast of Kenya. About 1.4 million people resided in Kilifi County by 2016 of whom the majority (61\%) were rural dwellers and $22 \%$ were aged $10-20$ years [53]. Kilifi is termed as a "medium HIV county" with 45 per 1000 affected of whom 6000 (19\%) were youth and young adults, aged 1524 years [50]. About $891 \mathrm{~km}^{2}$ of Kilifi County is covered by Kilifi Health and Demographic Surveillance System (KHDSS) [54], a region with various ongoing CGMRCKEMRI research activities.

Perinatally HIV infected and perinatally HIV exposed but uninfected adolescents and their caregivers were recruited through sequential sampling from all families that attended HIV clinic days at eight HIV treatment and care clinics at health facilities (hospitals and health centres) in Kilifi County. Recruitment was conducted by a trained research assistant in liaison with health workers at the participating HIV treatment facilities. Some of the perinatally HIV exposed but uninfected adolescents and their caregivers were also recruited by visiting families affected with HIV within their community with the assistance of a community health worker based at an HIV clinic. HIV unexposed and uninfected adolescents were randomly sampled among households within the KHDSS using the KHDSS population register [54].

Medical records at the health facilities were used to confirm perinatally HIV-infected adolescents' HIV status. As part of the eligibility criteria, the adolescents had to be fully aware of their HIV status and that of their biological mother. The adolescent's awareness of maternal HIV status was an important criterion for abating the ethical dilemma and emotional burden for example, tension and mistrust, that can potentially arise from the abrupt awareness of the source of HIV infection by the adolescents participating in this study and the members of their household. HIV exposure of perinatally HIV exposed but uninfected adolescents was ascertained from maternal medical records (antenatal care cards) confirming HIV infection of the mother during pregnancy. Additionally, recent medical records of the adolescent (if available) were used to ascertain that the perinatally HIV exposed but uninfected adolescent was HIV uninfected. The perinatally HIV exposed but uninfected adolescent also had to be aware of his or her biological mothers' HIV status for study eligibility. HIV unexposed and uninfected adolescents were not directly tested for HIV but recruitment was restricted to those whose mothers willingly shared their HIV test results at the time of their pregnancy with the participating adolescent. For both perinatally HIV exposed but uninfected adolescents and HIV unexposed and uninfected adolescents, a brief screening checklist was utilized to exclude adolescents who had experienced severe childhood illness or 
were having recurring health problems so as to minimize the possibility of including HIV-infected adolescents among the control group. Besides, a more detailed assessment of the adolescents' medical history, symptoms, and concerns was also done by a trained clinician during the assessments for data collection. All eligible adolescent participants had to be accompanied by a legal caretaker during their appointment for data collection at the CGMRC-KEMRI. Monetary reimbursement of 300 Kenyan shillings (about 3 US dollars) and a transport fee reimbursement were given to the accompanying caretaker and a snack was provided to all participants prior to the assessments. Ethical approval to conduct this study was obtained from the Kenya Medical Research Institute Scientific and Ethics Review Unit (KEMRI/SERU/CGMR-C/084/ 3454). Permission was also obtained from the Kilifi County government, department of health services (HP/KCHS/ VOL.VIX/80).

The current study comprises 558 (199 HIV unexposed and uninfected, 158 perinatally HIV exposed but uninfected, and 201 perinatally HIV infected) adolescents aged $12-17$ years. Initially, 638 potentially eligible adolescent participants (227 HIV unexposed and uninfected, 185 perinatally HIV exposed but uninfected, and 226 perinatally HIV infected) had shown interest in participating, but 560 ultimately took part. Of these 560 , data on HRB outcomes from 2 participants was completely missing, therefore they were excluded. Nonresponse $(n=78)$ was mainly attributable to silent refusal (i.e., lack of follow-up in making or attending visits $(n=39$, $50 \%$ ), or to direct refusal of further contact with the research team $(n=9,11.5 \%)$, to the failure to meet inclusion criteria $(n=7,8.9 \%)$, and to participant relocation $(n=2,2.6 \%))$. Some eligible participants were not scheduled for an assessment after attaining the required sample size quotas $(n=21$, $27 \%$ ). Overall, the non-respondents did not differ by HIV group composition (34.6\% HIV unexposed and uninfected, $34.6 \%$ perinatally HIV exposed but uninfected and 30.8\% perinatally HIV infected) and sex distribution $(p=0.75)$. However, among the non-respondents, the HIV unexposed and uninfected group was the oldest (mean $=13.9$ years, $\mathrm{SD}=1.7, p=0.002$ ).

\section{Informed Consent}

Informed consent was obtained from all the individual participants included in the study. Written parental or guardian consent as well as adolescents' assent were obtained.

\section{Measures}

\section{Health Behavior Outcomes}

HRB, the primary outcome of this study, was assessed using an audio-computer assisted self-interview (ACASI) of the
Kilifi Health Risk Behavior Questionnaire (KRIBE-Q) in Swahili language. The KRIBE-Q was previously adapted and validated for use among the adolescent sub-population in Kilifi and is a reliable (Gwet $\mathrm{ACl}=0.82$ ) measure for adolescents' HRB [55]. Contextually relevant examples and explanations of HRB were utilized in the interviews for clarity. In summary, the reported behaviors comprised the following:

Injury or Violence-Related Behavior Six injury and violencerelated behaviors were reported: (i) was engaged in physical fights within the past 12 months; (ii) was seriously injured within the past 12 months; (iii) experienced dating violence (physical and/or sexual) within the past 12 months; (iv) was forced to have sexual intercourse; (v) was bullied within the past 12 months; and (vi) experienced suicidal behavior (ideation and/or attempt) within the past 12 months.

Sexual Risk Behavior Three behaviors reported on sexual risk behavior were (i) early sexual debut (dichotomized initiation of sex before 14 years or at 14 years and above); (ii) engagement in transactional sex (victim and/or perpetrator) in the past 12 months; and (iii) condom nonuse during most recent sex.

Substance Use Behavior Tobacco and alcohol use were categorized into one group as both are examples of licit substances that are largely accessible within the Kenyan context [56]. Marijuana and Khat were grouped together in a second category as central nervous stimulants [57], which was fairly accessible by youths within the study setting [58]. A third categorization was for other drug use. The five substance use behaviors reported were (i) lifetime use of tobacco or alcohol products, (ii) recent use (past 30 days) of tobacco or alcohol products, (iii) lifetime use of marijuana and Khat products, (iv) recent use (past 30 days) of marijuana and Khat products, and (v) lifetime use of other drugs.

Poor Hygiene Behavior Two indications of poor oral hygiene and poor general body hygiene were reported. Respondents were asked how often they cleaned or brushed their teeth in a regular week and how often they washed their entire bodies with water and soap during a regular week.

Gambling Gambling behaviors were captured by an item asking if the adolescent ever spent much more than they planned on gambling activities within the past 12 months.

Physical Activity and Sedentary Behavior Three behaviors on physical activity and sedentary behavior were reported: (i) number of days of vigorous physical activity (at least $10 \mathrm{~min}$ at a time) during a regular week, (ii) number of days of moderate physical activity (at least $10 \mathrm{~min}$ at a time) during a regular week, and (iii) number of hours spent on sedentary 
activities during a regular day. Contextually relevant examples and explanations of sedentary behavior and vigorous and moderate forms of physical activity were utilized in the interviews for purposes of clarification.

Dietary Behavior Dietary behaviors were captured by assessing the frequency of (i) fruit and vegetable consumption and (ii) fatty or fast food intake during a regular week.

\section{Executive Functioning}

Three core EF domains, namely working memory, inhibitory control, and cognitive flexibility [59], were assessed. All EF assessments were administered by a research assistant (trained in psychological and cognitive assessment) in quiet and properly lit rooms, arranged to minimize any form of distractions. Standardized procedures for administration of each EF test were followed.

Cognitive Flexibility Five trails of the comprehensive trail making test (CTMT) were administered in numerical order following the standardized procedure [60]. Raw scores for each trial (number of seconds taken by an examinee to complete the trial) were recorded by the assessor. T-scores per trial were obtained from the CTMT examiner's manual [60] and performance summarized by the average T-scores for all completed trials.

Inhibitory Control The Stroop color and word test (SCWT) [61] was administered to assess inhibitory control. Study reports have shown a link between deficits in the ability to inhibit cognitive interference (inhibitory control) and impulsivity $[62,63]$. From the three sections of the test (each timed for $45 \mathrm{~s}$ ), the raw word score (words correctly identified), raw color score (correctly identified colors), and the raw colorword score (correctly identified color of ink for a contrasting name of color) were recorded by the assessor per examinee. The interference score was computed by subtracting the raw color score from the raw color-word score.

Working Memory Participants were administered the backward digit span and the letter-number sequencing (LNS) subsets. These tasks have been previously modified for use with children, adolescents, and older populations within the study setting [64]. Scores were the total number of correct sequences (total correct raw scores) for both LNS and backward digit span tasks.

\section{Other Variables}

The adolescents' age, sex, current educational level, and orphanhood status were captured and ascertained in the presence of their caretaker as well as from records such as birth certificates. The adolescents' caretakers were also asked about their household socio-economic status using an assets index that has been extensively utilized in the Kilifi context [65]. Adolescents' weight and height were measured according to recommended procedures [66]. Body mass index for age (BMI for age) and height for age were then computed using the WHO standards [67]. Items assessing parent-to-adolescent interaction, peer-to-peer relationship, and school attachment were from measures previously utilized in adolescent subpopulations [68-70]. The most suitable items for each of the three components were selected based on factor analytic approach. Additional items were taken from the KRIBE-Q [55] and assessed "household food insecurity" in the past 30 days (asking if one went hungry because there was not enough food at home), "feeling unsafe in their neighborhood," "experience of mental distress" (feeling sad/hopeless almost every day for 2 weeks or more in a row) within the past 12 month, and "use of tobacco products by their caretaker/s." A blood sample was taken from the perinatally HIV-infected adolescents and analyzed for $\mathrm{CD} 4 / \mathrm{CD} 8$ cell count and HIV viral load concentrations.

\section{Statistical Analyses}

All analyses were conducted in the STATA15 software package (StataCorp LLC). First, latent class analysis (LCA) [71] was performed to identify behavioral classes based on the 22 behaviors described above. Five models varying from one to five latent classes were generated and the Akaike information criterion (AIC) and Bayesian information criterion (BIC) were utilized to select the model with the best goodness of fit indices and lowest BIC values [72]. Assignment of participants to respective latent classes was based on their posterior probabilities of class membership. Entropy was also measured to indicate the level of separation between classes. Values of normalized entropy greater than 0.80 indicate that the latent classes are highly discriminating [73].

The HRB composition, socio-demographic factors (sex, age, socio-economic status, education level, household food insecurity), biological factors (BMI, height for age, medical history, HIV status, CD4/CD8 cell count, HIV viral load concentrations), and psychosocial factors (mental distress, orphanhood, caregiver-adolescent interaction, caregiver tobacco use, school attachment, peer-peer relationship, feelings about neighborhood safety) of each class from the optimal model were summarized using descriptive statistics of proportions (\%) and means. Bivariate analyses (Chi-square test or Fisher exact test for categorical variables and analysis of variance [ANOVA] with Bonferroni correction for post-hoc analysis for continuous variables) were used to test for significance of differences in HRB composition, socio-demographic, and biological and psychosocial factors across the behavioral classes. ANOVA with Bonferroni correction for post-hoc analysis 
was performed to identify differences in EF outcomes across classes. A directed acyclic graph (DAG) of the hypothesized exposure-outcome relationship was generated in DAGitty V2.3 open access software [74] (see Fig. 1). The exposureoutcome relationship relies on prior knowledge from other empirical studies and assumed contributory effects which were explained in the introduction section of this article. Using the DAG, we identified variables for adjustment (also known as minimum sufficient adjustment sets) in estimating the effect of perinatal HIV status on HRB clustering. DAGs are increasingly utilized in modern epidemiology and are found to be crucial in advancing investigation of causal relationships which involve multiple interrelated variables [75, 76]. DAGs are also useful for avoiding the introduction of collider bias (i.e., conditional associations introduced by selected covariates) and identifying confounding [77]. Multinomial logistic regression was conducted to investigate the association between perinatal HIV infection and HRB clustering while controlling for the variables identified from the DAG model as minimum sufficient adjustment sets. Multiple imputation was used for data missing at random on individual behavioral variables due to non-response [78].

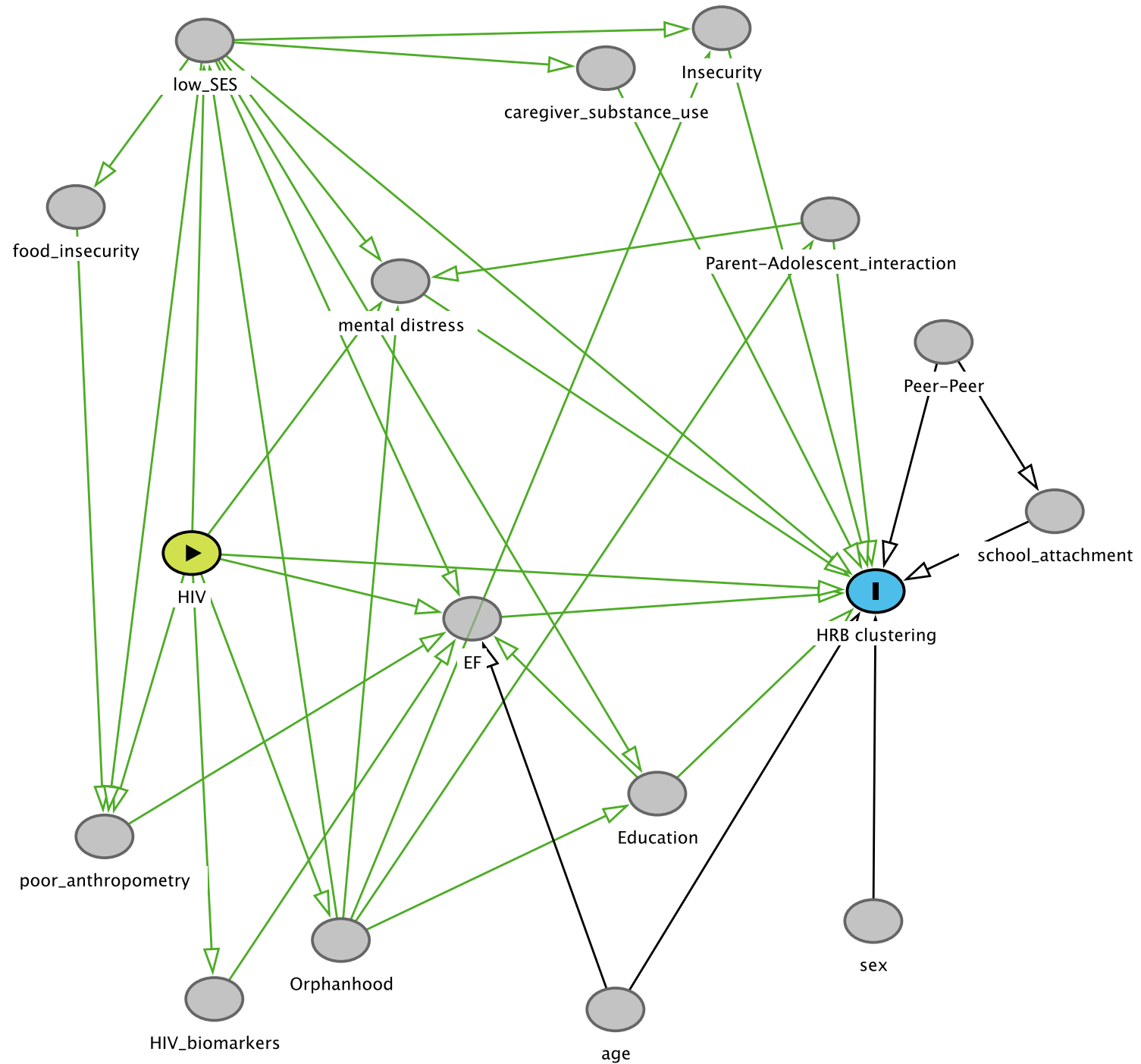

Fig. 1 A directed acyclic graph (DAG) conceptualizing the effect of perinatal HIV infection on health risk behavior clustering among adolescents. HIV: perinatal HIV infection, HRB clustering: Health risk behavior clustering, EF: Measure of executive functioning domains of working memory, inhibitory control and cognitive flexibility, Low_SES: Low household socio-economic status, Sex: sex of the adolescent, Age: age of the adolescent, HIV_biomarkers: HIV treatment outcomes (CD4/CD8 cell count and HIV viral load concentrations), Poor_anthropometry: poor adolescent anthropometric measures of body mass index and height for age, Orphanhood: being an orphan, Education: adolescent's current

educational level, Food_insecurity: household food insecurity in the past 30 days, Mental_distress: Experience of mental distress within the past 12 months, Caregiver_substance use: Use of substances by the caretaker, Insecurity: Feeling unsafe in their neighborhood, Parent adolescent interaction: Parent-to-adolescent interaction, Peer-peer: Peer-to-peer relationship, School_attachment: School attachment, ( $)$ Exposure, (I) Outcome, $\longrightarrow$ : Other Variables, $\longrightarrow$ : Causal path, $\longrightarrow$ : Biasing path 


\section{Results}

\section{Sample Characteristics}

The final sample comprised 558 adolescents (36\% perinatally HIV infected, $28.3 \%$ perinatally HIV exposed but uninfected, and $35.7 \%$ HIV unexposed and uninfected) with a mean age of 13.7 ( $\mathrm{SD}=1.6)$. The perinatally HIV exposed but uninfected were slightly younger $(13.3( \pm 1.4)$ years $)$ than the other groups, with the oldest being the perinatally HIV infected (14.1 $( \pm 1.6)$ years) $(F=11.9, p<0.001)$. Overall, $53 \%$ were females and no differences in sex were found across HIV groups $(p=0.72)$. Almost all participants $(99 \%)$ attended school, with a majority (93\%) being at primary education level. Group differences in education were not significant $(p=0.06)$. All the perinatally HIV-infected adolescents were enrolled on ART of whom $17.5 \%$ were prescribed protease inhibitor-based regimen (i.e., second line regimen).

\section{Behavioral Classes}

The four-class solution was found to be the best fitting model as it had the lowest BIC $(12,238.06)$ and adequate power for the entropy measure (0.85) to indicate a high level of discrimination by the 4 latent classes (see Table 1).

The four behavioral classes generated were class 1 (The substance and drug abstinent low risk takers), class 2 (The physically very active and moderate risk takers), class 3 (The high risk takers with poor hygiene), and class 4 (The highest risk takers). Below is a description of the composition and characteristics of these four behavioral classes.

\section{Class 1 (the Substance and Drug Abstinent Low Risk Takers)}

This behavioral class comprised the majority $(52 \%)$ of the adolescent study participants (see Table 2). These adolescents reported the lowest occurrence of alcohol, tobacco, and other drug use behavior $(0-4.8 \%)$. They also reported the least occurrence of gambling behavior. The adolescents in class 1 reported the least engagement in sexual risk behavior, although their reports were similar to those from the adolescents in class 2 . The reports of injury and violence-related behavior in this first class were generally lower than in classes 3 and 4 , but comparable to the reports in behavioral class 2 , with exception of engagement in physical fights and being bullied (reports on bullying were lower in class 1 compared to 2) and dating violence (reports on dating violence were lower in class 2 compared to 1). However, the adolescents in behavioral class 1 reported low levels of engagement in moderate and vigorous physical activity (i.e., less than 2 days per week of at least 10 min of physical activity). Their level of engagement in physical activity was significantly lower than that reported in the behavioral classes 2 and 4 . Their reports of hygiene behavior were comparable to those reported in behavioral class 2, but much better than those of class 3 .

\section{Class 2 (the Physically Very Active and Moderate Risk Takers)}

This behavioral class comprised $24 \%$ of the adolescent sample. Their reports on engagement in sexual risk behavior, injury, and violence-related behavior and hygiene behavior were much better than reports from classes 3 and 4, and minimally different from the reports from class 1 (see Table 2). However, this second class compared to behavioral class 1 had significantly poorer reports that indicated more frequent occurrence of physical fights $(p=0.005)$, experience of bullying $(p<0.001)$, lifetime use of other drugs $(p=0.02)$, recent tobacco and/or alcohol use $(p=0.01)$, fatty food intake $(p<0.001)$, and gambling behavior $(p<0.001)$. Noteworthy, adolescents from behavioral class 2 reported the highest engagement in moderate physical activity (on average 6 days of at least 10 min of activity per week) and their engagement in vigorous physical activity was significantly higher than that of adolescents in classes 1 and 3.

\section{Class 3 (the High Risk Takers with Poor Hygiene)}

This behavioral class comprised $18 \%$ of the adolescents. Overall, they reported greater occurrence of violence and injury-related behaviors (11.1-59.6\%), substance use (3.0 $58.6 \%$ ), sexual risk behavior (8.1-12.1\%), gambling behavior $(22.2 \%)$, poor fruit and vegetable consumption $(31.3 \%)$, and
Table 1 Model fit information for the latent class models from 1 to 5 clusters $(n=558)$

\begin{tabular}{lllll}
\hline Number of clusters & Degrees of freedom & AIC & BIC & Entropy \\
\hline 1 & 24 & $12,628.51$ & $12,732.3$ & \\
2 & 47 & $12,208.32$ & $12,411.57$ & 0.56 \\
3 & 68 & $11,959.72$ & $12,253.78$ & 0.87 \\
4 & 90 & $11,848.87$ & $12,238.06$ & 0.85 \\
5 & 113 & $11,816.23$ & $12,304.89$ & 0.80 \\
\hline
\end{tabular}

AIC Akaike information criterion, BIC Bayesian information criterion. The optimal latent class model is highlighted in italic 


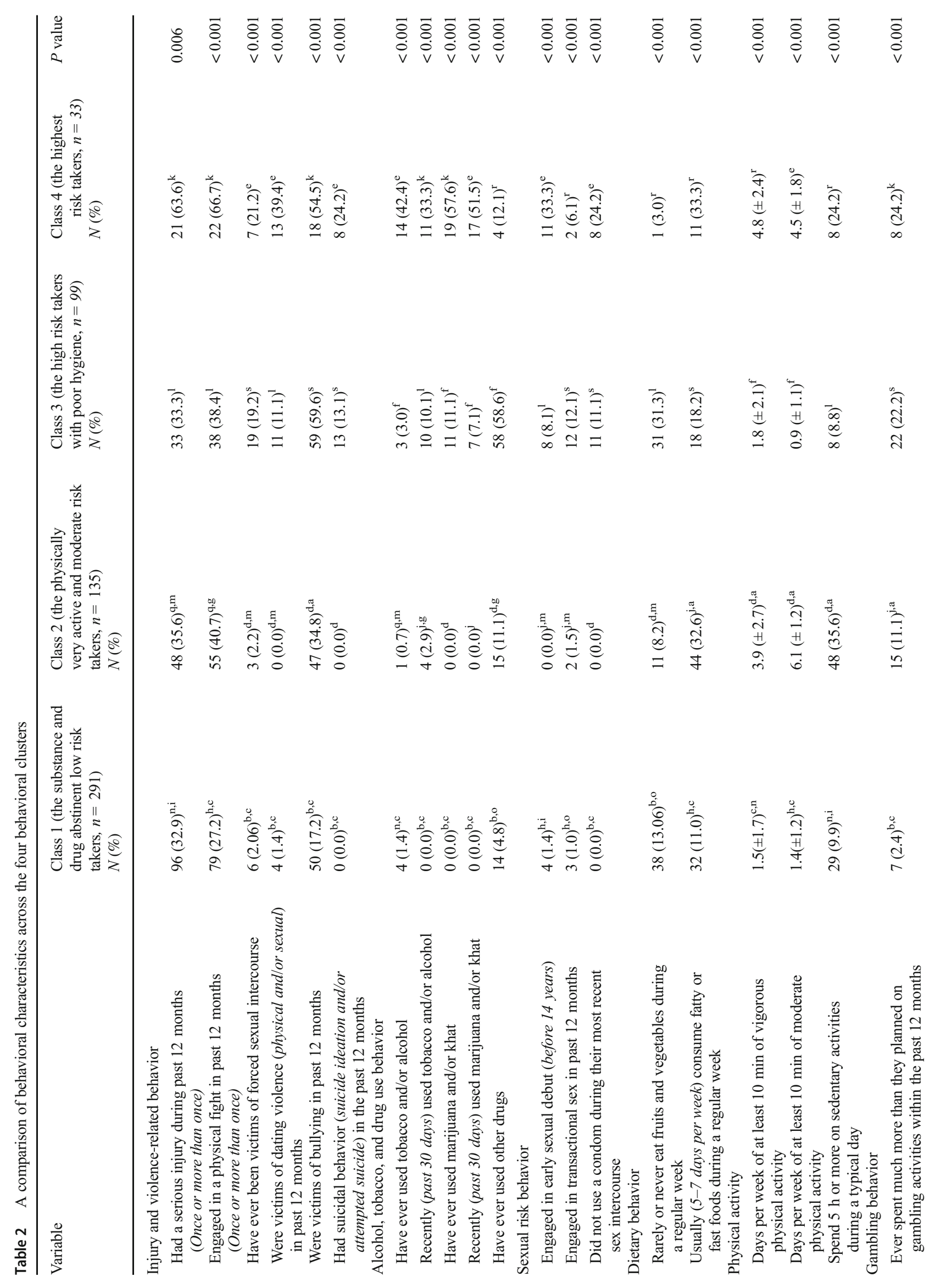




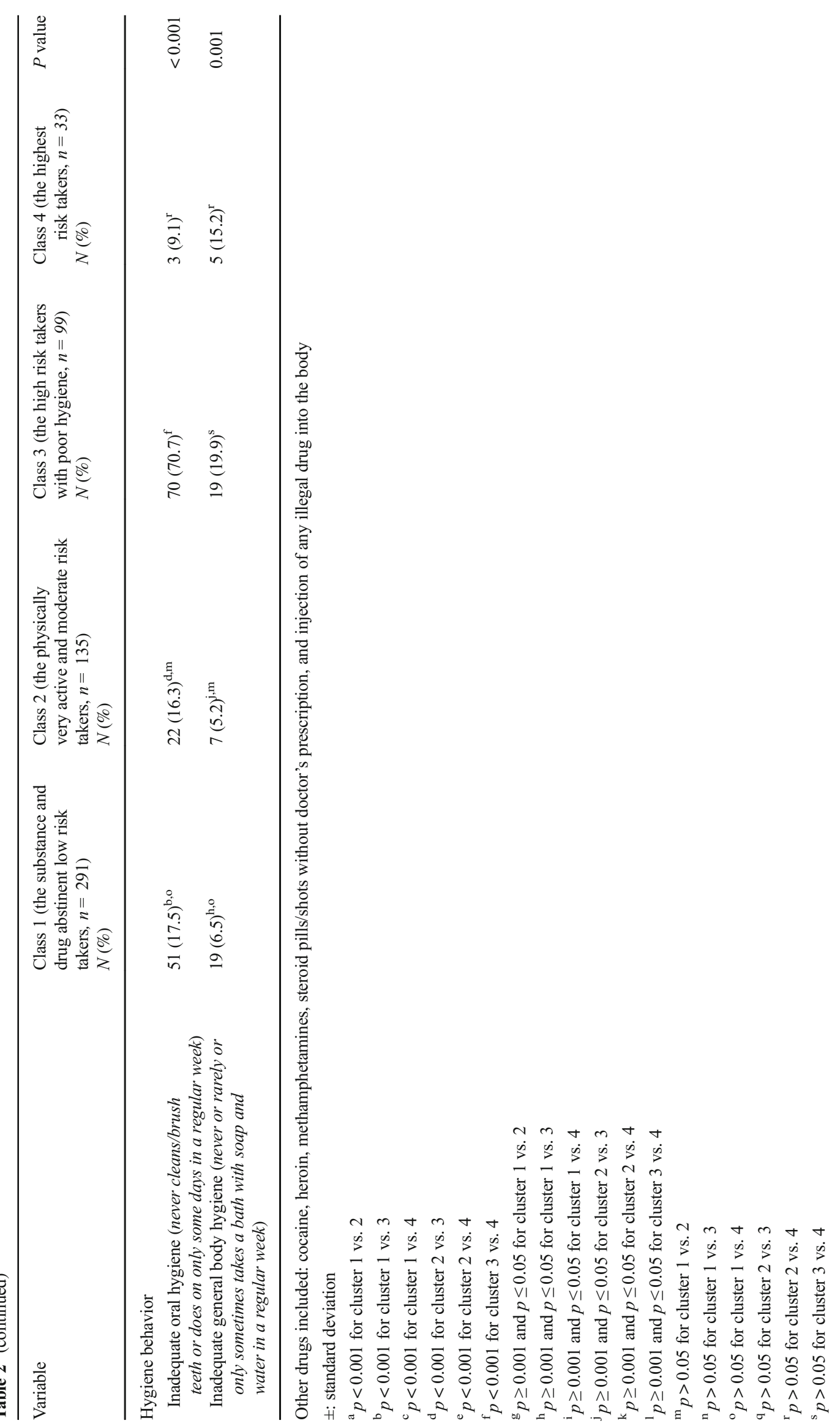


Table 3 Socio-demographic, psychosocial, and biomedical characteristics of participants in the 4 behavioral clusters

\begin{tabular}{|c|c|c|c|c|c|}
\hline Factors & $\begin{array}{l}\text { Class } 1 \text { (the substance and } \\
\text { drug abstinent low risk } \\
\text { takers, } n=291) \\
N(\%)\end{array}$ & $\begin{array}{l}\text { Class } 2 \text { (the physically very } \\
\text { active and moderate risk } \\
\text { takers, } n=135) \\
N(\%)\end{array}$ & $\begin{array}{l}\text { Class } 3 \text { (the high risk } \\
\text { takers with poor } \\
\text { hygiene, } n=99) \\
N(\%)\end{array}$ & $\begin{array}{l}\text { Class } 4 \text { (the } \\
\text { highest risk } \\
\text { takers, } n=33) \\
N(\%)\end{array}$ & $P$ value \\
\hline HIV status & $\mathrm{P}^{\mathrm{n}, \mathrm{o}}$ & $\mathrm{P}^{\mathrm{q}, \mathrm{m}}$ & $\mathrm{P}^{\mathrm{s}}$ & $\mathrm{P}^{\mathrm{r}}$ & 0.686 \\
\hline HIV uninfected unexposed & $103(35.4)$ & $47(34.8)$ & $38(38.4)$ & $11(33.3)$ & \\
\hline $\begin{array}{l}\text { Perinatally HIV exposed } \\
\text { uninfected }\end{array}$ & $90(30.9)$ & $37(27.4)$ & $21(21.2)$ & $10(30.3)$ & \\
\hline Perinatally HIV infected & $98(33.7)$ & $51(37.8)$ & $40(40.4)$ & $12(36.4)$ & \\
\hline Adolescence stage & $\mathrm{P}^{\mathrm{h}, \mathrm{o}}$ & $\mathrm{P}^{\mathrm{j}, \mathrm{m}}$ & $\mathrm{P}^{1}$ & $\mathrm{P}^{\mathrm{r}}$ & 0.027 \\
\hline Early adolescence (10-14 years) & $195(67.1)$ & $92(68.1)$ & $79(79.8)$ & $18(54.5)$ & \\
\hline Mid-adolescence (15-17 years) & $96(32.9)$ & $43(31.9)$ & $20(20.2)$ & $15(45.5)$ & \\
\hline Sex (males) & $126(43.3)^{\mathrm{n}, \mathrm{i}}$ & $67(49.6)^{\mathrm{q}, \mathrm{m}}$ & $46(46.5)^{1}$ & $24(72.7)^{\mathrm{k}}$ & 0.013 \\
\hline Age (years) & $13.7( \pm 1.5)^{\mathrm{n}, \mathrm{i}}$ & $13.8( \pm 1.5)^{\mathrm{q}, \mathrm{m}}$ & $13.4( \pm 1.6)^{1}$ & $14.5( \pm 1.5)^{\mathrm{r}}$ & 0.004 \\
\hline Education & $\mathrm{P}^{\mathrm{b}, \mathrm{o}}$ & $\mathrm{P}^{\mathrm{d}, \mathrm{m}}$ & $\mathrm{P}^{1}$ & $\mathrm{P}^{\mathrm{r}}$ & 0.001 \\
\hline Not attending school & $2(0.7)$ & $0(0.0)$ & $2(2.0)$ & $1(3.0)$ & \\
\hline Special school & $2(0.7)$ & $0(0.0)$ & $1(1.0)$ & $0(0.0)$ & \\
\hline $\begin{array}{l}\text { Lower primary school } \\
\quad \text { (pre-primary to class 5) }\end{array}$ & $139(47.7)$ & $59(43.7)$ & $71(71.7)$ & $11(33.4)$ & \\
\hline Upper primary school (class 6-8) & $134(46.1)$ & $62(45.9)$ & $23(23.3)$ & $17(51.5)$ & \\
\hline Secondary school & $14(4.8)$ & $14(10.4)$ & $2(2.0)$ & $4(12.1)$ & \\
\hline Orphanhood & $\mathrm{P}^{\mathrm{n}, \mathrm{o}}$ & $\mathrm{P}^{\mathrm{q}, \mathrm{m}}$ & $\mathrm{P}^{\mathrm{s}}$ & $\mathrm{P}^{\mathrm{r}}$ & 0.492 \\
\hline Both parents alive & $191(65.6)$ & $98(72.6)$ & $65(65.7)$ & $22(66.7)$ & \\
\hline Only mother alive & $52(17.9)$ & $24(17.8)$ & $20(20.2)$ & $5(15.2)$ & \\
\hline Only father alive & $28(9.6)$ & $4(2.9)$ & $5(5.0)$ & $3(9.1)$ & \\
\hline Both parents died & $20(6.9)$ & $9(6.7)$ & $9(9.1)$ & $3(9.1)$ & \\
\hline $\begin{array}{l}\text { Caretaker uses substances } \\
\text { (tobacco use) }\end{array}$ & $44(15.1)^{\mathrm{h}, \mathrm{i}}$ & $37(27.4)^{\mathrm{q}, \mathrm{g}}$ & $28(28.3)^{\mathrm{s}}$ & $12(36.4)^{\mathrm{r}}$ & 0.003 \\
\hline $\begin{array}{l}\text { Caretaker-adolescent positive } \\
\text { interaction (total score of } \\
\text { tool ranges from } 0 \text { to } 72 \text { ) }\end{array}$ & $46.9( \pm 7.7)^{\mathrm{n}, \mathrm{o}}$ & $47.2( \pm 8.6)^{\mathrm{q}, \mathrm{m}}$ & $45.7( \pm 8.7)^{\mathrm{s}}$ & $44.3( \pm 7.3)^{\mathrm{r}}$ & 0.180 \\
\hline $\begin{array}{l}\text { School attachment (total score of } \\
\text { tool ranges from } 0 \text { to } 16 \text { ) }\end{array}$ & $12.4( \pm 2.3)^{\mathrm{n}, \mathrm{o}}$ & $13.2( \pm 2.1)^{\mathrm{q}, \mathrm{g}}$ & $12.5( \pm 2.7)^{\mathrm{s}}$ & $12.5( \pm 2.1)^{\mathrm{r}}$ & 0.013 \\
\hline $\begin{array}{l}\text { Peer to peer positive relationship } \\
\text { (total score of tool ranges from } \\
\text { ( to 12) }\end{array}$ & $9.1( \pm 2.3)^{\mathrm{n}, \mathrm{o}}$ & $9.3( \pm 2.3)^{\mathrm{q}, \mathrm{m}}$ & $8.8( \pm 2.8)^{\mathrm{s}}$ & $8.9( \pm 2.3)^{r}$ & 0.359 \\
\hline $\begin{array}{l}\text { Social economic status (total } \\
\text { score } \\
\text { of tool ranges from } 0 \text { to 9) }\end{array}$ & $1.6( \pm 1.4)^{\mathrm{n}, \mathrm{o}}$ & $2.0( \pm 1.7)^{\mathrm{j}, \mathrm{m}}$ & $1.4( \pm 1.3)^{\mathrm{s}}$ & $2.2( \pm 1.9)^{\mathrm{r}}$ & 0.006 \\
\hline $\begin{array}{l}\text { Food insecurity in past } 30 \text { days } \\
\text { (always/most of the } \\
\text { time/sometimes } \\
\text { going hungry due to no food at } \\
\text { home) }\end{array}$ & $32(11.0)^{\mathrm{h}, \mathrm{i}}$ & $23(17.0)^{\mathrm{q}, \mathrm{m}}$ & $20(20.2)^{\mathrm{s}}$ & $8(24.2)^{\mathrm{r}}$ & 0.037 \\
\hline $\begin{array}{l}\text { Feeling unsafe in their } \\
\text { neighborhood }\end{array}$ & $47(16.2)^{b, c}$ & $24(17.8)^{\mathrm{j}, \mathrm{m}}$ & $36(36.4)^{\mathrm{s}}$ & $15(45.5)^{\mathrm{k}}$ & $<0.001$ \\
\hline $\begin{array}{l}\text { Mental distress in past } 12 \text { months } \\
\text { (feeling sad or hopeless almost } \\
\text { every day for two weeks or } \\
\text { more in a row) }\end{array}$ & $34(11.7)^{b, c}$ & $28(20.7)^{\mathrm{j}, \mathrm{g}}$ & $39(39.4)^{\mathrm{s}}$ & $13(39.4)^{\mathrm{k}}$ & $<0.001$ \\
\hline $\begin{array}{l}\text { History of any other medical } \\
\text { conditions } \\
\text { (Epilepsy, Cerebral Palsy, } \\
\text { history of an } \\
\text { acute illness, Sickle cell } \\
\text { disease, Stroke, } \\
\text { any hospital admissions) }\end{array}$ & $85(29.2)^{\mathrm{n}, \mathrm{o}}$ & $40(29.6)^{\mathrm{q}, \mathrm{m}}$ & $36(36.4)^{\mathrm{s}}$ & $13(39.4)^{\mathrm{r}}$ & 0.222 \\
\hline Being stunted & $78(26.8)^{\mathrm{b}, \mathrm{i}}$ & $31(22.9)^{\mathrm{d}, \mathrm{m}}$ & $46(46.5)^{1}$ & $7(21.2)^{r}$ & $<0.001$ \\
\hline
\end{tabular}


Table 3 (continued)

\begin{tabular}{|c|c|c|c|c|c|}
\hline Factors & $\begin{array}{l}\text { Class } 1 \text { (the substance and } \\
\text { drug abstinent low risk } \\
\text { takers, } n=291) \\
N(\%)\end{array}$ & $\begin{array}{l}\text { Class } 2 \text { (the physically very } \\
\text { active and moderate risk } \\
\text { takers, } n=135) \\
N(\%)\end{array}$ & $\begin{array}{l}\text { Class } 3 \text { (the high risk } \\
\text { takers with poor } \\
\text { hygiene, } n=99) \\
N(\%)\end{array}$ & $\begin{array}{l}\text { Class } 4 \text { (the } \\
\text { highest risk } \\
\text { takers, } n=33) \\
N(\%)\end{array}$ & $P$ value \\
\hline BMI for age & $\mathrm{P}^{\mathrm{n}, \mathrm{o}}$ & $\mathrm{P}^{\mathrm{q}, \mathrm{m}}$ & $\mathrm{P}^{\mathrm{s}}$ & $\mathrm{P}^{\mathrm{r}}$ & 0.847 \\
\hline Thinness & $52(17.9)$ & $22(16.3)$ & $20(20.2)$ & $3(9.1)$ & \\
\hline Overweight or obese & $15(5.2)$ & $5(3.7)$ & $4(4.0)$ & $1(3.0)$ & \\
\hline $\begin{array}{l}\text { CD4 Cell count (specific for } \\
\text { perinatally } \\
\text { HIV infected } n=190 \text { ) }\end{array}$ & $\mathrm{P}^{\mathrm{n}, \mathrm{o}}$ & $\mathrm{P}^{\mathrm{q}, \mathrm{m}}$ & $\mathrm{P}^{\mathrm{s}}$ & $\mathrm{P}^{\mathrm{r}}$ & 0.126 \\
\hline$>500$ cells $/ \mathrm{mm}^{3}$ & $56(60.9)$ & $39(79.6)$ & $25(65.8)$ & $1(63.6)$ & \\
\hline $350-500$ cells $/ \mathrm{mm}^{3}$ & $11(11.9)$ & $4(8.2)$ & $7(18.4)$ & $3(27.3)$ & \\
\hline$<350$ cells $/ \mathrm{mm}^{3}$ & $25(27.2)$ & $6(12.2)$ & $6(15.8)$ & $1(9.1)$ & \\
\hline $\begin{array}{l}\text { HIV viral load concertation } \\
\text { (specific for perinatally HIV } \\
\text { infected } n=163 \text { ) }\end{array}$ & $\mathrm{P}^{\mathrm{n}, \mathrm{o}}$ & $\mathrm{P}^{\mathrm{q}, \mathrm{m}}$ & $\mathrm{P}^{\mathrm{s}}$ & $\mathrm{P}^{\mathrm{r}}$ & 0.643 \\
\hline$\leq 1000$ copies $/ \mathrm{ml}$ & $38(48.1)$ & $14(35.9)$ & $16(45.7)$ & $4(40.0)$ & \\
\hline
\end{tabular}

BMI: Body Mass Index

\pm : standard deviation

${ }^{\mathrm{a}} p<0.001$ for cluster 1 vs. 2

${ }^{\mathrm{b}} p<0.001$ for cluster 1 vs. 3

${ }^{\mathrm{c}} p<0.001$ for cluster 1 vs. 4

${ }^{\mathrm{d}} p<0.001$ for cluster 2 vs. 3

${ }^{\mathrm{e}} p<0.001$ for cluster 2 vs. 4

${ }^{\mathrm{f}} p<0.001$ for cluster 3 vs. 4

${ }^{\mathrm{g}} p \geq 0.001$ and $p \leq 0.05$ for cluster 1 vs. 2

${ }^{\mathrm{h}} p \geq 0.001$ and $p \leq 0.05$ for cluster 1 vs. 3

${ }^{\mathrm{i}} p \geq 0.001$ and $p \leq 0.05$ for cluster 1 vs. 4

${ }^{\mathrm{j}} p \geq 0.001$ and $p \leq 0.05$ for cluster 2 vs. 3

${ }^{\mathrm{k}} p \geq 0.001$ and $p \leq 0.05$ for cluster 2 vs. 4

${ }^{1} p \geq 0.001$ and $p \leq 0.05$ for cluster 3 vs. 4

${ }^{\mathrm{m}} p>0.05$ for cluster 1 vs. 2

${ }^{\mathrm{n}} p>0.05$ for cluster 1 vs. 3

${ }^{\circ} p>0.05$ for cluster 1 vs. 4

${ }^{\mathrm{q}} p>0.05$ for cluster 2 vs. 3

${ }^{\mathrm{r}} p>0.05$ for cluster 2 vs. 4

s $p>0.05$ for cluster 3 vs. 4

inadequate hygiene behavior (19.9-70.7\%) compared to members of behavioral classes 1 and 2 (see Table 2). Strikingly, reports from the majority (71\%) of the adolescents in class 3 indicated inadequate oral hygiene and 59\% reported lifetime use of other drugs. The occurrence of both of these health risk behaviors was significantly higher than in any other behavioral class. The adolescents of class 3 also reported the poorest levels of engagement in moderate physical activity, and they showed a similar level of engagement in vigorous physical activity as reported in class 1 .

\section{Class 4 (the Highest Risk Takers)}

This behavioral class comprised the smallest proportion (6\%) of the adolescent study sample. The adolescents in this class presented with significantly higher reports of injury and violence related behavior, sexual risk behavior, alcohol, tobacco and other drug use, and gambling behavior as compared to reports from classes 1 and 2. Although there was some extent of similarity in the burden of risky behavior between class 4 and 3, higher reports of serious injuries in the past 12 months 
$(p=0.002)$, fights $(p=0.005)$, dating violence $(p=0.001)$, early sexual debut $(p<0.001)$, both recent and lifetime use of tobacco/alcohol and marijuana/khat $(p<0.001-p=0.004)$, and sedentary hours $(p=0.014)$ were found in class 4 compared to class 3 . However, the adolescents in class 4 reported the lowest rates of inadequate oral hygiene $(9.1 \%)$ and they did have the lowest reports on poor fruit and vegetable consumption $(3 \%)$ across the four behavior classes. They also reported significantly higher levels of engagement in moderate and vigorous physical activity compared to the adolescents in class 1 and 3 (see Table 2).

\section{Socio-demographic, Biological and Psycho-Social Characteristics of the Four Behavioral Classes}

Results from bivariate analysis of various factors across the behavioral classes are summarized in Table 3. No significant differences were found in HIV group distribution across the four classes $(p=0.69)$. About a quarter of the adolescents in each HIV group (26\% of perinatally HIV infected, $20 \%$ of perinatally HIV exposed but uninfected, and $25 \%$ of the HIV unexposed and uninfected) belonged to the two highest risk classes (i.e., classes 3 and 4). The majority of the adolescents in behavioral class 4 (the highest risk takers) were male and generally older $(p=0.004)$ than the adolescents in other behavioral classes. Across all four behavioral classes, class 3 (the high risk takers with poor hygiene) comprised the greatest proportion of young adolescents with the lowest educational achievement (75\% below upper primary school) and the group with the highest rate of nutritional stunting (all differences were statistically significant). In class 1 (the substance and drug abstinent low risk takers), significantly fewer reports of caretaker tobacco use (15.1\%) and adolescents' mental distress in the past 12 months (11.7\%) were found compared to the other three behavioral classes. School attachment was significantly better in class 2 (the high physically active moderate risk takers) compared to class $1(p=0.008)$ and social economic status was higher for the adolescents in class 2 compared to those in class $3(p=0.026)$. Adolescents in both class 1 and class 2 had significantly fewer reports of food insecurity and feeling unsafe in the neighborhood in comparison to the riskier behavioral classes of 3 and 4 .

\section{EF Outcomes Across the Four Behavioral Classes}

Results from the ANOVA to identify differences in EF outcomes across classes revealed that significant differences in performance on all the four EF tasks exist across the behavioral classes (see Table 4). The adolescents in class 3 had the lowest scores $(p<0.001)$ on both tasks of working memory (i.e., Backward digit span and LNS). The adolescents in class 3 also had the lowest mean T-scores on cognitive flexibility and they had the highest Stroop interference scores, but these differences were only statistically significant in comparison to scores for the lower risk classes (i.e., classes 1 and 2).

\section{Findings from DAG}

The minimum sufficient adjustment sets, which were the identified variables for adjustment, from the DAG (see Fig. 1) were executive functioning, experience of mental distress, household socio-economic status, parent-to-adolescent

Table 4 Summary of scores of executive functioning (backward digit span, letter-number sequencing, Stroop interference, and comprehensive trail making) and their association with behavioral cluster membership

\begin{tabular}{|c|c|c|c|c|c|}
\hline Executive functioning & $\begin{array}{l}\text { Class } 1 \text { (the substance } \\
\text { and drug abstinent low } \\
\text { risk takers, } n=291 \text { ) } \\
N(\%)\end{array}$ & $\begin{array}{l}\text { Class } 2 \text { (the physically } \\
\text { very active and moderate } \\
\text { risk takers, } n=135) \\
N(\%)\end{array}$ & $\begin{array}{l}\text { Class } 3 \text { (the high risk takers } \\
\text { with poor hygiene, } n=99) \\
N(\%)\end{array}$ & $\begin{array}{l}\text { Class } 4 \text { (the highest } \\
\text { risk takers, } n=33 \text { ) } \\
N(\%)\end{array}$ & $\begin{array}{l}P \\
\text { value }^{\mathrm{a}}\end{array}$ \\
\hline $\begin{array}{l}\text { Backward digit span (total } \\
\text { correct raw scores) }\end{array}$ & $3.7( \pm 2.9)$ & $4.2( \pm 2.8)$ & $2.2( \pm 2.4)$ & $4.3( \pm 3.3)$ & $<0.001$ \\
\hline $\begin{array}{l}\text { Letter-number sequencing } \\
\quad(\text { total correct raw scores) }\end{array}$ & $4.9( \pm 2.3)$ & $5.2( \pm 2.3)$ & $3.3( \pm 1.4)$ & $4.8( \pm 2.3)$ & $<0.001$ \\
\hline $\begin{array}{l}\text { Stroop Interference (raw } \\
\text { scores) }\end{array}$ & $-16.1( \pm 11.0)$ & $-16.9( \pm 9.9)$ & $-12.8( \pm 10.8)$ & $-15.7( \pm 9.6)$ & 0.025 \\
\hline $\begin{array}{l}\text { Comprehensive trail making } \\
\quad \text { (mean T-scores) }^{\mathrm{e}}\end{array}$ & $24.9( \pm 5.1)$ & $25.5( \pm 5.1)$ & $22.9( \pm 3.9)$ & $24.8( \pm 5.6)$ & 0.0007 \\
\hline \multicolumn{6}{|l|}{$\pm:$ Confidence Interval } \\
\hline \multicolumn{6}{|c|}{${ }^{a} P$ values for the post-hoc analysis (Bonferroni correction) in ANOVA } \\
\hline \multicolumn{6}{|c|}{ b Backward digit span- measures working memory (increasing scores reveal better working memory) } \\
\hline \multicolumn{6}{|c|}{${ }^{\mathrm{c}}$ Letter-number sequencing — measures working memory (increasing scores reveal better working memory) } \\
\hline \multicolumn{6}{|c|}{${ }^{\mathrm{d}}$ Stroop interference - measures inhibitory control (increasing scores reveal worse inhibitory control abilities) } \\
\hline
\end{tabular}


Table 5 Results from a multinomial logistic regression model showing the association between adolescents' perinatal HIV status and membership to behavioral clusters

\begin{tabular}{|c|c|c|c|c|c|c|c|}
\hline & $\begin{array}{l}\text { RRR, 95\% } \\
\text { confidence interval }\end{array}$ & $\begin{array}{l}P \\
\text { value }\end{array}$ & $\begin{array}{l}\text { RRR, 95\% } \\
\text { confidence interval }\end{array}$ & $P$ value & $\begin{array}{l}\text { RRR, 95\% } \\
\text { confidence interval }\end{array}$ & $\begin{array}{l}P \\
\text { value }\end{array}$ & $\begin{array}{l}\text { Overall } P \\
\text { value }\end{array}$ \\
\hline Variable $^{\mathrm{a}}$ & Class 2 vs. class 1 & & Class 3 vs. class 1 & & Class 4 vs. class 1 & & \\
\hline HIV status ${ }^{\mathrm{b}}$ & & & & & & & 0.366 \\
\hline Perinatally HIV exposed uninfected & $0.8(0.46,1.38)$ & 0.42 & $0.49(0.25,0.98)$ & 0.045 & $1.37(0.50,3.72)$ & 0.54 & \\
\hline Perinatally HIV infected & $1.1(0.66,1.85)$ & 0.70 & $0.66(0.36,1.23)$ & 0.195 & $1.00(0.38,2.67)$ & 0.99 & \\
\hline $\begin{array}{l}\text { Letter-number sequencing (total correct } \\
\text { raw scores) }\end{array}$ & $1.0(0.89,1.13)$ & 0.90 & $0.73(0.61,0.87)$ & $p<0.001$ & $0.89(0.71,1,12)$ & 0.32 & 0.0037 \\
\hline $\begin{array}{l}\text { Mental distress in past } 12 \text { months (No } \\
\text { distress-reference) }\end{array}$ & $1.9(1.12,3.49)$ & 0.019 & $3.86(2.15,6.93)$ & $p<0.001$ & $3.82(1.64,8.91)$ & 0.002 & $<0.001$ \\
\hline $\begin{array}{l}\text { Feeling unsafe in their neighborhood } \\
\text { (Feeling safe-reference) }\end{array}$ & $1.09(0.61,1.91)$ & 0.77 & $2.09(1.18,3.73)$ & 0.011 & $3.87(1.69,8.8)$ & 0.001 & 0.002 \\
\hline Age (years) & $0.97(0.82,1.17)$ & 0.82 & $0.86(0.69,1.05)$ & 0.15 & $1.38(1.02,1.88)$ & 0.037 & 0.047 \\
\hline
\end{tabular}

$v s$ versus, $R R R$ relative risk ratio

Class 1: the substance and drug abstinent low risk takers; class 2 : the physically very active and moderate risk takers; class 3 : the high risk takers with poor hygiene; class 4: the highest risk takers

${ }^{\text {a }}$ Only variables that were statistically significant or had a statistically significant category are presented

${ }^{\mathrm{b}} \mathrm{HIV}$ uninfected unexposed is the reference group for HIV status

interaction, feeling unsafe in their neighborhood, age, and current educational level. These variables were adjusted in the model for estimating the effect of perinatal HIV status on HRB clustering.

\section{Association Between Perinatal HIV Status and Behavioral Class Membership}

The factors associated with behavioral class membership are summarized in Table 5. The results from an adjusted multinomial logistic regression model indicate that working memory (as measured by the letter number sequencing task) ( $p=$ 0.0037 ), adolescent's experience of mental distress within the past 12 months $(p<0.001)$, adolescent's feeling of insecurity within the neighborhood $(p=0.002)$, and age of the adolescent $(p=0.047$ ) are significantly associated with HRB clustering. Noteworthy, the risk of belonging to behavioral class 3 relative to class 1 reduces by $27 \%$ for every unit increase in a score of working memory as measured on the letter number sequencing task ( $R R R=0.73, p<0.001)$. The risk of belonging to classes of higher behavioral risk (i.e., classes 2, 3, and 4) relative to class 1 increases twice or higher among adolescents who experienced mental distress within the past 12 months and the results are statistically significant across all the behavioral classes. The risk of belonging to the behavioral classes 3 and 4 relative to class 1 increases more than twice among adolescents who feel unsafe in their neighborhood. A unit increase in age of the adolescent was associated with $38 \%$ increase in risk of belonging to behavioral class 4 relative to class 1 ( $R R R=1.38, p=0.037)$. Finally, although perinatal HIV status did not have an overall significant association with HRB cluster membership $(p=0.366)$, there was borderline significance $(p=0.045)$ for a protective effect against membership to class 3 relative to class 1 for adolescents who were perinatally HIV exposed but uninfected $(\mathrm{RRR}=0.49)$.

\section{Discussion}

In the present study, we identified four distinct behavioral classes with varying levels of HRB burden and clustering among an adolescent sub-population from a low resource setting in Kenya. The majority (slightly more than a half) of these adolescents belonged to the class with the least reports of HRB occurrence and clustering. However, we found that almost a quarter of the adolescents belonged to two behavioral classes with the highest occurrence of multiple forms of HRB. This segment of adolescents may potentially represent a vulnerable sub-population with shared cumulative psychosocial risk factors which underlie an unhealthy lifestyle [10]. Our findings of the four class solution are similar to reports from other studies on HRB clustering conducted among rural Chinese [79], Canadian [80], and Dutch adolescents [11]. The proportion of adolescents in the highest risk class (5.9\%) in this present study was close to composition of the highest risk group (4\%) among rural Chinese adolescents [79], whose mean age (14.7 years) was also similar to the age of our participants (13.7 years). However, these findings should be interpreted cautiously since the other studies did not focus on adolescents living with HIV, were from different geographical settings, and measured behaviors that were different from the ones reported in this study. This stated, our findings do emphasize that clustering of HRB among adolescents in rural coastal Kenya is of concern. More importantly, there exists a 
segment of the adolescents with heightened vulnerability to multiple forms of HRB and thus targeted risk reduction and prevention interventions are urgently required to address this problem.

Another key finding is that our hypothesis that perinatal HIV infection is associated with HRB clustering was not supported by the study findings. Overall, we did not find a significant association between perinatal HIV status (regardless of the HIV specific biomarkers) and HRB clustering. We had suggested that HIV infection introduces extra adversity and HIV associated neurocognitive deficits, which could heighten vulnerability for HRB. We propose two plausible explanations for the absence of this association. First, the access to services such as proper counseling, socio-emotional support, and home visitation received through HIV care and treatment clinics potentially lessens the impacts of psychosocial adversity among adolescents living with HIV, thereby enhancing their healthy lifestyle [81]. Noteworthy, all the adolescents living with HIV in our study were enrolled in comprehensive HIV care and treatment clinics. Second, we suggest that adolescents who experienced HIV-associated neurocognitive impairment may benefit from HIV medication and experiencedependent neuroplasticity across the lifespan, which improves their resilience and lessens the severity of long-term consequences (e.g., EF deficits) and the implications on their mental and behavioral outcomes [82]. Notably, our findings on the lack of differences in HRB outcomes across the HIV groups in our study are consistent with previous studies from SSA [3] and the USA [19]. These findings stress that children born to HIV-infected women are equally at risk for multiple forms of HRB, which emphasizes the need for adolescent-friendliness of public health services. Such services would help to attract young people regardless of their HIV status and to retain them in continuous care. Guidelines for provision of adolescent youth friendly services in Kenya were formulated in 2005 [73]; however, more effort is still needed to improve coverage of adolescent friendly services within the Kenyan healthcare system [83].

Although we found various significant differences in behavior composition across the four classes, there was generally a high and cross-cutting burden of various forms of injury and violence related behavior, poor hygiene, inadequate physical activity, and poor dietary behavior. Similar to these findings, poor sanitation and hygiene conditions [84], dietary and physical activity transition [85], and a high burden of violence-related behavior, such as bullying [86], have been reported among adolescents in Kenya in other studies. It is plausible that extreme household poverty coupled with psychosocial adversity are highly prevalent in this study setting and potentially predispose the general adolescent subpopulation to shared forms of HRB. Indeed, some indication of shared vulnerability and adversity in this setting is illustrated by our findings of extremely low mean scores (1.8 out of the maximum 9) on the socio-economic status index, coupled by the high proportion (32\%) of orphaned adolescents (without differences by HIV status), frequent reports of food insecurity (18\%), and low levels of caretaker-adolescent positive interaction (an average score of $64 \%$ on the scale we utilized in the study). All these factors combined are likely to exacerbate mental distress among the adolescents, and a large body of evidence has linked mental distress to HRB in adolescence $[25,26]$. Corroboratively, we found that the risk of membership to behavioral classes with a greater burden of HRB clustering increased when adolescents reported a history of mental distress within the past 12 months. Noting that most of the factors which could increase psychosocial adversity are household or family level factors, there is a need for appropriate interventions that enhance good parenting practices such as parental or caregiver involvement and responsive communication and which incorporate aspects on poverty alleviation.

Another key finding is that our assumption that deficits in EF may predispose adolescents to HRB clustering was supported by our study findings. However, this effect was not HIV group specific as we presupposed. Specifically, we found that better working memory and cognitive flexibility were associated with a lower burden of HRB clustering. Moreover, the protective effects of working memory still persisted after multivariate analysis. Similar to the findings in this present study, stronger working memory has been shown to regulate adolescents' HRB, like substance use [35], and sexual risk taking [36]. Plausibly, the effects of cognitive flexibility could be masked by the effects of educational achievement because these two are closely linked [87]. These findings stress the need to incorporate interventions which stimulate EF development in preventive/behavioral interventions. Of note, such interventions have already been found beneficial when they also address social, physical, and emotional needs [88]. Hence, our findings add to the existing literature regarding the link between $\mathrm{EF}$ and $\operatorname{HRB}[35,89]$.

The findings from our study indicate that a high burden of victimization, internalizing problems, and suicidal behavior distinguished the adolescents within the top two risky behavioral classes. Victimization (sexual, physical, emotional) [90], emotional, and behavioral problems [91] are commonly reported as major concerns for adolescents within the Kenyan setting. The findings on clustering of victimization, suicidal behavior, and other forms of HRB like sexual risk and substance use among the adolescents in behavioral classes 3 and 4 are corroborated by an existing body of research showing that victimized adolescents may experience an elevated burden of suicidal behavior [92] alongside maladaptive behavior such as substance use [93]. Nonetheless, more research is needed to 
better understand the pathways and specific associations between victimization and engagement in forms of HRB. Additionally, screening for victimization during adolescence and the provision of post-violence and mental health services should be incorporated among routine adolescent health promotion programs within this study setting.

Finally, we found that older adolescents are at an increased risk of membership to a behavioral class of higher HRB burden. This finding is consistent with results from other studies on multiple HRB among adolescents $[94,95]$. Hence the relevance of age-appropriate interventions when addressing HRB during adolescence is highlighted. This finding also suggests that it may not be sufficient to collate adolescent age (10-19 years) into a single set when studying health behavior and lifestyle. Rather, adolescence should be subcategorized into different developmental stages like early and late adolescence to better understand health outcomes and specific needs of this sub-population.

\section{Strengths and Weaknesses}

To the best of our knowledge, this is the first study from SSA that investigates adolescents' HRB clustering, utilizing a variety of behaviors, which simultaneously involves adolescents from three HIV groups (i.e., perinatally HIV infected, perinatally HIV exposed but uninfected, and HIV unexposed and uninfected). The study also elaborates the role of EF in HRB clustering; an area that has not been previously studied within the adolescent sub-population in SSA. Nonetheless, this study was conducted among adolescents from a poor rural setting and of a young age (mean $=13.7$ years), who may not necessarily be representative of the general adolescent subpopulation in Kenya, for example those living in urban and less impoverished backgrounds. Also, the adolescents living with HIV were perinatally infected, were all enrolled in HIV care, and had been fully disclosed of their HIV status. It is plausible that their HRB outcomes and/or predictors differ from those of adolescents who acquired HIV behaviorally or those who are not enrolled in treatment or not aware of their HIV status. Nonetheless, aggregating perinatally HIV infected and behaviorally infected adolescent groups could potentially blur unique outcomes and this has been cautioned against [96]. Furthermore, this study so far was based on a crosssectional design, which makes directionality of associations challenging to ascertain. HRB was self-reported and this could have introduced some social desirability bias. However, such bias was to a large extent countered by the ACASI method of questionnaire administration. This is because this method does not involve face-to-face interview delivery, but rather an audio-recorded voice guides the participant through the interview questions, which enhances privacy, especially when reporting on sensitive topics.

\section{Conclusion}

Despite some limitations, the present findings have important implications for clinicians and policy makers. First, adolescents born to HIV-infected mothers from poor rural settings are equally as vulnerable to HRB as their uninfected peers. This highlights the urgent need for inclusive and multicomponent interventions which are tailored to the adolescents' early or later developmental stage, and simultaneously address multiple forms of HRB. Such interventions could be made more inclusive and comprehensive by implementing them within rural adolescent HIV primary health clinics. Caregivers and family members could be actively involved through program components that address household psychosocial risk factors like poverty; and by incorporating services to promote mental health and EF development. Future longitudinal studies are needed to examine mechanisms which underlie HRB clustering and the changes in lifestyle that occur across the adolescents' developmental stage.

Acknowledgements This study was funded by the Initiative to Develop African Research Leaders (IDeAL) Wellcome Trust award (Grant number 107769/Z/15/Z) and the UK Medical Research Council (MRC) and the UK Department for International Development (DFID) under MRC/ DFID Concordant agreement (Grant number MR/M025454/1). The funding bodies do not have any role in the design of this study, collection, analysis, interpretation, and writing of this manuscript. The authors wish to thank all the adolescents that participated in this study. We also thank health facility managers and staff, as well as the adolescents' caregivers for their support during this study. We also thank Beatrice Kabunda, Esther Chongwo, Karabu Ngombo, Khamis Katana, Richard Karisa, and Vincent Amukumbi for their role in data collection.

\section{Compliance with Ethical Standards}

Conflict of Interest The authors declare that they have no conflict of interest.

Ethical Approval All procedures performed in studies involving human participants were in accordance with the ethical standards of the institutional and/or national research committee and with the 1964 Helsinki declaration and its later amendments or comparable ethical standards.

Open Access This article is licensed under a Creative Commons Attribution 4.0 International License, which permits use, sharing, adaptation, distribution and reproduction in any medium or format, as long as you give appropriate credit to the original author(s) and the source, provide a link to the Creative Commons licence, and indicate if changes were made. The images or other third party material in this article are included in the article's Creative Commons licence, unless indicated otherwise in a credit line to the material. If material is not included in the article's Creative Commons licence and your intended use is not permitted by 
statutory regulation or exceeds the permitted use, you will need to obtain permission directly from the copyright holder. To view a copy of this licence, visit http://creativecommons.org/licenses/by/4.0/.

\section{References}

1. Idele P, Gillespie A, Porth T, et al. Epidemiology of HIV and AIDS among adolescents: current status, inequities, and data gaps. J Acquir Immune Defic Syndr. 2014;66:S144-53.

2. Lowenthal ED, Bakeera-Kitaka S, Marukutira T, Chapman J, Goldrath K, Ferrand RA. Perinatally acquired HIV infection in adolescents from sub-Saharan Africa: a review of emerging challenges. Lancet Infect Dis. 2014;14(7):627-39.

3. Ssewanyana D, Mwangala PN, van Baar A, Newton CR, Abubakar A. Health risk behaviour among adolescents living with HIV in subSaharan Africa: a systematic review and meta-analysis. Biomed Res Int. 2018;2018.

4. Toska E, Pantelic M, Meinck F, Keck K, Haghighat R, Cluver L. Sex in the shadow of HIV: a systematic review of prevalence, risk factors, and interventions to reduce sexual risk-taking among HIVpositive adolescents and youth in sub-Saharan Africa. PLoS One. 2017;12(6):e0178106.

5. Steinberg L. A social neuroscience perspective on adolescent risktaking. Dev Rev. 2008;28(1):78-106.

6. Jessor R. Risk behavior in adolescence: a psychosocial framework for understanding and action. J Adolesc Health. 1991;12(8):597605.

7. Kim MH, Mazenga AC, Yu X, Ahmed S, Paul ME, Kazembe PN, et al. High self-reported non-adherence to antiretroviral therapy amongst adolescents living with HIV in Malawi: barriers and associated factors. J Int AIDS Soc. 2017;20(1):21437.

8. Gamarel KE, Nichols S, Kahler CW, Westfall AO, Lally MA, Wilson CM. A cross-sectional study examining associations between substance use frequency, problematic use and STIs among youth living with HIV. Sex Transm Infect. 2018;94(4):304-8.

9. Sithole Z, Mbizvo E, Chonzi P, et al. Virological failure among adolescents on ART, Harare City, 2017-a case-control study. BMC Infect Dis. 2018;18(1):469.

10. Spring B, Moller AC, Coons MJ. Multiple health behaviours: overview and implications. J Public Health. 2012;34(suppl_1):i3-i10.

11. Busch V, Van Stel HF, Schrijvers AJ, de Leeuw JR. Clustering of health-related behaviors, health outcomes and demographics in Dutch adolescents: a cross-sectional study. BMC Public Health. 2013;13(1):1118.

12. Dumith SC, Muniz LC, Tassitano RM, Hallal PC, Menezes AM. Clustering of risk factors for chronic diseases among adolescents from southern Brazil. Prev Med. 2012;54(6):393-6.

13. Park Y-D, Patton LL, Kim H-Y. Clustering of oral and general health risk behaviors in Korean adolescents: a national representative sample. J Adolesc Health. 2010;47(3):277-81.

14. Schuit AJ, van Loon AJM, Tijhuis M, Ocké MC. Clustering of lifestyle risk factors in a general adult population. J Prev Med. 2002;35(3):219-24.

15. Lynch J, Smith GD. A life course approach to chronic disease epidemiology. Annu Rev Public Health. 2005;26:1-35.

16. Nolan S, Walley AY, Heeren TC, Patts GJ, Ventura AS, Sullivan $\mathrm{MM}$, et al. HIV-infected individuals who use alcohol and other drugs, and virologic suppression. AIDS Care. 2017;29(9):1129-36.

17. Abubakar A, Van de Vijver FJ, Fischer R, et al. Everyone has a secret they keep close to their hearts: challenges faced by adolescents living with HIV infection at the Kenyan coast. BMC Public Health. 2016;16(1):197.
18. Kidman R, Nachman S, Dietrich J, Liberty A, Violari A. Childhood adversity increases the risk of onward transmission from perinatal HIV-infected adolescents and youth in South Africa. Child Abuse Negl. 2018;79:98-106.

19. Mellins CA, Tassiopoulos K, Malee K, et al. Behavioral health risks in perinatally HIV-exposed youth: co-occurrence of sexual and drug use behavior, mental health problems, and nonadherence to antiretroviral treatment. AIDS Patient Care STDs. 2011;25(7):413-22.

20. Abubakar A, Van de Vijver FJ, Hassan AS, et al. Cumulative psychosocial risk is a salient predictor of depressive symptoms among vertically HIV-infected and HIV-affected adolescents at the Kenyan coast. Glob Public Health. 2017;83(5-6):743-52.

21. Nedelcovych MT, Manning AA, Semenova S, Gamaldo C, Haughey NJ, Slusher BS. The psychiatric impact of HIV. ACS Chem Neurosci. 2017;8(7):1432-4.

22. Bhana A, Mellins CA, Small L, et al. Resilience in perinatal HIV+ adolescents in South Africa. AIDS Care. 2016;28(sup2):49-59.

23. Mellins CA, Malee KM. Understanding the mental health of youth living with perinatal HIV infection: lessons learned and current challenges. J Int AIDS Soc. 2013;16(1):18593.

24. Desmond C, Michael K, Gow J. The hidden battle: HIV/AIDS in the household and community. S Afr J Int Aff. 2000;7(2):39-58.

25. Wilson K, Asbridge M, Kisely S, Langille D. Associations of risk of depression with sexual risk taking among adolescents in Nova Scotia high schools. Can J Psychiatr. 2010;55(9):577-85.

26. Brooks TL, Harris SK, Thrall JS, Woods ER. Association of adolescent risk behaviors with mental health symptoms in high school students. J Adolesc Health. 2002;31(3):240-6.

27. Boivin MJ, Barlow-Mosha L, Chernoff MC, Laughton B, Zimmer B, Joyce C, et al. Neuropsychological performance in African children with HIV enrolled in a multisite antiretroviral clinical trial. AIDS. 2018;32(2):189-204.

28. Hoare J, Fouche J-P, Phillips N, Joska JA, Myer L, Zar HJ, et al. Structural brain changes in perinatally HIV-infected young adolescents in South Africa. AIDS. 2018;32(18):2707-18.

29. Kerr SJ, Puthanakit T, Malee KM, Thongpibul K, Ly PS, Sophonphan J, et al. Increased risk of executive function and emotional behavioral problems among Virologically well-controlled perinatally HIV-infected adolescents in Thailand and Cambodia. J Acquir Immune Defic Syndr. 2019;82(3):297-304.

30. Phillips N, Amos T, Kuo C, et al. HIV-associated cognitive impairment in perinatally infected children: a meta-analysis. Pediatrics. 2016;138(5):e20160893.

31. Thompson PM, Dutton RA, Hayashi KM, et al. Thinning of the cerebral cortex visualized in HIV/AIDS reflects CD4+ T lymphocyte decline. Proc Natl Acad Sci. 2005;102(43):15647-52.

32. Ketzler S, Weis S, Haug H, Budka H. Loss of neurons in the frontal cortex in AIDS brains. Acta Neuropathol. 1990;80(1):92-4.

33. Shah A, Gangwani MR, Chaudhari NS, Glazyrin A, Bhat HK, Kumar A. Neurotoxicity in the post-HAART era: caution for the antiretroviral therapeutics. Neurotox Res. 2016;30(4):677-97.

34. Boissé L, Gill MJ, Power C. HIV infection of the central nervous system: clinical features and neuropathogenesis. Neurol Clin. 2008;26(3):799-819.

35. Peeters M, Janssen T, Monshouwer K, Boendermaker W, Pronk T, Wiers R, et al. Weaknesses in executive functioning predict the initiating of adolescents' alcohol use. Dev Cogn Neurosci. 2015;16:139-46.

36. Khurana A, Romer D, Betancourt LM, Brodsky NL, Giannetta JM, Hurt H. Stronger working memory reduces sexual risk taking in adolescents, even after controlling for parental influences. Child Dev. 2015;86(4):1125-41.

37. Piche J, Kaylegian J, Smith D, Hunter S. The relationship between self-reported executive functioning and risk-taking behavior in urban homeless youth. Behavioral Sciences. 2018;8(1):6. 
38. Hackman DA, Gallop R, Evans GW, Farah MJ. Socioeconomic status and executive function: developmental trajectories and mediation. Dev Sci. 2015;18(5):686-702.

39. Park H, Bothe D, Holsinger E, Kirchner HL, Olness K, Mandalakas A. The impact of nutritional status and longitudinal recovery of motor and cognitive milestones in internationally adopted children. Int J Environ Res Public Health. 2011;8(1):105-16.

40. Best JR, Miller PH, Naglieri JA. Relations between executive function and academic achievement from ages 5 to 17 in a large, representative national sample. Learn Individ Differ. 2011;21(4):327-36.

41. Sontag LM, Graber JA, Brooks-Gunn J, Warren MP. Coping with social stress: implications for psychopathology in young adolescent girls. J Abnorm Child Psychol. 2008;36(8):1159-74.

42. Resnick MD, Bearman PS, Blum RW, Bauman KE, Harris KM, Jones J, et al. Protecting adolescents from harm: findings from the National Longitudinal Study on adolescent health. JAMA. 1997;278(10):823-32.

43. Oyewole BK, Animasahun VJ, Chapman HJ. Tobacco use in Nigerian youth: a systematic review. PLoS One. 2018;13(5): e0196362.

44. Leão A, Moura NS, Gonçalves E, Silva D, Silva R, Thomazzi S. Simultaneous health risk behaviors in adolescents associated with higher economic class in the northeast of Brazil. Sci World J. 2017;2017:3587567.

45. Kilpatrick DG, Acierno R, Saunders B, Resnick HS, Best CL, Schnurr PP. Risk factors for adolescent substance abuse and dependence: data from a national sample. J Consult Clin Psychol. 2000;68(1):19-30.

46. Ssewanyana D, Mwangala PN, Marsh V, Jao I, van Baar A, Newton $\mathrm{CR}$, et al. Young people's and stakeholders' perspectives of adolescent sexual risk behavior in Kilifi County, Kenya: a qualitative study. J Health Psychol. 2018;23(2):188-205.

47. Doyle AM, Mavedzenge SN, Plummer ML, Ross DA. The sexual behaviour of adolescents in sub-Saharan Africa: patterns and trends from national surveys. Tropical Med Int Health. 2012;17(7):796807.

48. Cubbin C, Santelli J, Brindis CD, Braveman P. Neighborhood context and sexual behaviors among adolescents: findings from the National Longitudinal Study of adolescent health. Perspect Sex Reprod Health. 2005;37(3):125-34.

49. Shope JT, Bingham CR. Teen driving: motor-vehicle crashes and factors that contribute. American Journal of Prev Med. 2008;35(3): S261-S71.

50. National AIDS and STI Control Program (NASCOP). Kenya HIV County Profiles 2016. http://nacc.or.ke/kenya-hiv-county-profiles/. Accessed 20 October 2018.

51. National Council for Population and Development (NCPD). 2015 Kenya National Adolescents and Youth Survey. http://www.ncpd. go.ke/2015-national-adolescent-and-youth-survey-preliminaryreport/. Accessed 20 October 2018..

52. Hassan AS, Nabwera HM, Mwaringa SM, Obonyo CA, Sanders EJ, Rinke de Wit TF, et al. HIV-1 virologic failure and acquired drug resistance among first-line antiretroviral experienced adults at a rural HIV clinic in coastal Kenya: a cross-sectional study. AIDS Res Ther. 2014;11(1):9.

53. National AIDS Control Council (NACC). Kilifi County HIV and AIDS Strategic Plan (2016-2020): A healthy and productive population. http://nacc.or.ke/kenya-hiv-county-profiles/. Accessed 10 December 2018.

54. Scott JAG, Bauni E, Moisi JC, Ojal J, Gatakaa H, Nyundo C, et al. Profile: the Kilifi health and demographic surveillance system (KHDSS). Int J Epidemiol. 2012;41(3):650-7.

55. Ssewanyana D, van Baar A, Newton CR, Abubakar A. A contextually relevant approach to assessing health risk behavior in a rural sub-Saharan Africa setting: the Kilifi health risk behavior questionnaire. BMC Public Health. 2018;18(1):774.
56. National AutAhority for the Campaign Against Alcohol and Drug Abuse (NACADA). Rapid Situation Assessment of the Status of Drug and Substance Abuse in Kenya, 2012. https://scadkenya.files. wordpress.com/2017/01/rapid-assessment-drug-and-substanceabuse-situation-kenya-20122.pdf. Accessed 20 October 2018.

57. United Nations Office on Drugs and Crime (UNODC). Treatment of stimulant use disorders: current practices and promising perspectives. Discussion paper. https://www.unodc.org/documents/drugprevention-and-treatment/Treatment_of_PSUD_for_website_24. 05.19.pdf. Accessed 10 January 2020.

58. Ssewanyana D, Mwangala PN, Marsh V, et al. Socio-ecological determinants of alcohol, tobacco, and drug use behavior of adolescents in Kilifi County at the Kenyan coast. J Health Psychol. 2018;1359105318782594.

59. Collins A, Koechlin E. Reasoning, learning, and creativity: frontal lobe function and human decision-making. PLoS Biol. 2012;10(3): e1001293.

60. Reynolds CR. Comprehensive trail making test (CTMT). Austin, TX: Pro-Ed 2002;408.

61. Golden CJ, Freshwater SM. Stroop color and word test. 1978.

62. Logan GD, Schachar RJ, Tannock R. Impulsivity and inhibitory control. Psychol Sci. 1997;8(1):60-4.

63. Roberts W, Fillmore MT, Milich R. Linking impulsivity and inhibitory control using manual and oculomotor response inhibition tasks. Acta Psychol. 2011;138(3):419-28.

64. Alcock KJ, Holding P, Mung'ala-Odera V, Newton C. Constructing tests of cognitive abilities for schooled and unschooled children. $\mathrm{J}$ Cross-Cult Psychol. 2008;39(5):529-51.

65. Abubakar A, Van de Vijver F, Van Baar A, et al. Socioeconomic status, anthropometric status, and psychomotor development of Kenyan children from resource-limited settings: a path-analytic study. Early Hum Dev. 2008;84(9):613-21.

66. World Health Organization (WHO). The WHO STEPwise approach to chronic disease risk factor surveillance (STEPS). Geneva. 2005.

67. World Health Organization (WHO). WHO AnthroPlus for personal computers Manual: Software for assessing growth of the world's children and adolescents. Geneva. 2009.

68. Armsden GC, Greenberg MT. The inventory of parent and peer attachment: individual differences and their relationship to psychological well-being in adolescence. J Youth Adolesc. 1987;16(5): $427-54$

69. Dekovic M, Engels RCME, Shirai T, De Kort G, Anker AL. The role of peer relations in adolescent development in two cultures: the Netherlands and Japan. J Cross-Cult Psychol. 2002;33(6):577-95.

70. Abubakar A, van de Vijver FJ, Alonso-Arbiol I, et al. Assessing sense of school belonging across cultural contexts using the PSSM: measurement and functional invariance. J Psychoeduc Assess. 2016;34(4):380-8.

71. Hagenaars JA, AL MC. Applied latent class analysis: Cambridge University Press; 2002.

72. Nylund KL, Asparouhov T, Muthén BO. Deciding on the number of classes in latent class analysis and growth mixture modeling: a Monte Carlo simulation study. Struct Equ Modeling. 2007;14(4): 535-69.

73. Kenyan Ministry of Health. National guidelines for provision of adolescent youth-friendly services (YFS) in Kenya. Nairobi. 2005.

74. Textor J, Hardt J, Knüppel S. DAGitty: a graphical tool for analyzing causal diagrams. Epidemiology. 2011;22(5):745.

75. Suttorp MM, Siegerink B, Jager KJ, Zoccali C, Dekker FW. Graphical presentation of confounding in directed acyclic graphs. Nephrol Dial Transpl. 2014;30(9):1418-23.

76. Moffa G, Catone G, Kuipers J, Kuipers E, Freeman D, Marwaha S, et al. Using directed acyclic graphs in epidemiological research in psychosis: an analysis of the role of bullying in psychosis. Schizophr Bull. 2017;43(6):1273-9. 
77. Shrier I, Platt RW. Reducing bias through directed acyclic graphs. BMC Med Res Methodol. 2008;8(1):70.

78. Graham JW, Olchowski AE, Gilreath TD. How many imputations are really needed? Some practical clarifications of multiple imputation theory. Prev Sci. 2007;8(3):206-13.

79. Ji Y, Xu H, Zhang Y, Liu Q. Heterogeneity of adolescent health risk behaviors in rural western China: a latent class analysis. PLoS One. 2018;13(6):e0199286.

80. Laxer RE, Brownson RC, Dubin JA, Cooke M, Chaurasia A, Leatherdale ST. Clustering of risk-related modifiable behaviours and their association with overweight and obesity among a large sample of youth in the COMPASS study. BMC Public Health. 2017;17(1):102.

81. Mutumba M, Mugerwa H, Musiime V, et al. Perceptions of strategies and intervention approaches for HIV self-management among Ugandan adolescents: a qualitative study. J Int Assoc Provid AIDS Care. 2019;18:2325958218823246.

82. Glasper ER, Neigh GN. Experience-dependent neuroplasticity across the lifespan: from risk to resilience. Front Behav Neurosci. 2019;12:335.

83. Godia PM, Olenja JM, Lavussa JA, Quinney D, Hofman JJ, Van Den Broek N. Sexual reproductive health service provision to young people in Kenya; health service providers' experiences. BMC Health Serv Res. 2013;13(1):476.

84. Alexander KT, Oduor C, Nyothach E, et al. Water, sanitation and hygiene conditions in Kenyan rural schools: are schools meeting the needs of menstruating girls? Water. 2014;6(5):1453-66.

85. Keding G. Nutrition transition in rural Tanzania and Kenya. World Rev Nutr Diet. 2016;115:68-81.

86. Brown DW, Riley L, Butchart A, Kann L. Bullying among youth from eight African countries and associations with adverse health behaviors. Pediatr Health. 2008;2(3):289.

87. Yeniad N, Malda M, Mesman J, van IJzendoorn MH, Pieper S. Shifting ability predicts math and reading performance in children: a meta-analytical study. Learn Individ Differ. 2013;23:1-9.
88. Diamond A, Ling DS. Conclusions about interventions, programs, and approaches for improving executive functions that appear justified and those that, despite much hype, do not. Dev Cogn Neurosci. 2016;18:34-48.

89. Romer D, Betancourt LM, Brodsky NL, Giannetta JM, Yang W, Hurt H. Does adolescent risk taking imply weak executive function? A prospective study of relations between working memory performance, impulsivity, and risk taking in early adolescence. Dev Sci. 2011;14(5):1119-33.

90. Mwangi MW, Kellogg TA, Brookmeyer K, Buluma R, Chiang L, Otieno-Nyunya B, et al. Perpetrators and context of child sexual abuse in Kenya. Child Abuse Negl. 2015;44:46-55.

91. Magai DN, Malik JA, Koot HM. Emotional and behavioral problems in children and adolescents in Central Kenya. Child Psychiatry Hum Dev. 2018:1-13.

92. Holt MK, Vivolo-Kantor AM, Polanin JR, Holland KM, DeGue S, Matjasko JL, et al. Bullying and suicidal ideation and behaviors: a meta-analysis. Pediatrics. 2015;135(2):e496-509.

93. Pinchevsky GM, Fagan AA, Wright EM. Victimization experiences and adolescent substance use: does the type and degree of victimization matter? J Interpers Violence. 2014;29(2):299-319.

94. ALdS B, Hardman CM, MVGd B. Prevalence and factors associated with the co-occurrence of health risk behaviors in adolescents. Rev Paul Pediatr. 2015;33(4):423-30.

95. Sychareun V, Thomsen S, Faxelid E. Concurrent multiple health risk behaviors among adolescents in Luangnamtha province. Lao PDR BMC Public Health. 2011;11(1):36.

96. Sherr L, Cluver L, Toska E, He E. Differing psychological vulnerabilities among behaviourally and perinatally HIV infected adolescents in South Africa-implications for targeted health service provision. AIDS Care. 2018:1-10.

Publisher's Note Springer Nature remains neutral with regard to jurisdictional claims in published maps and institutional affiliations. 